\title{
"I drink": Mothers' alcohol consumption as both individualised and imposed occupation
}

\author{
Lizahn G Cloete BSc OT (UWC); MSc OT (UCT); PhD OT (UCT) \\ Lecturer in Occupational Therapy, Interdisciplinary Health Sciences, Stellenbosch University
}

Elelwani L Ramugondo BSc OT (UCT); MSc OT (UCT); PhD OT (UCT)

Associate Professor in Occupational Therapy division, Department of Health and Rehabilitation Sciences, University of Cape Town

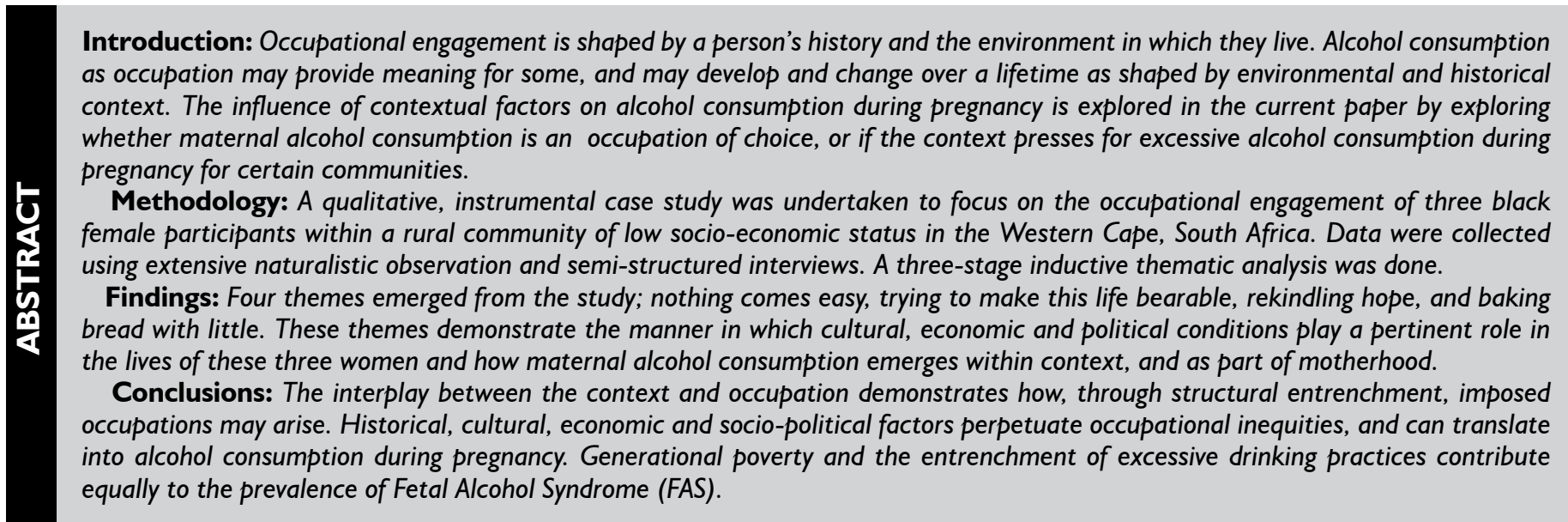

Key words: generational poverty; maternal alcohol consumption as occupation; imposed occupations; Fetal Alcohol Syndrome

\section{INTRODUCTION}

Fetal alcohol Syndrome (FAS) is the result of maternal alcohol consumption during pregnancy. Currently, FAS is known to be the leading cause of mental and physical handicap in communities worldwide'. The high prevalence of FAS internationally $(0.5$ to 2 cases per 1000 live births in the United States) but more so in certain communities in South Africa (up to 46.4/ I 000 live births) ${ }^{2}$ challenges occupational therapists to re-evaluate the interplay between contextual factors and the occupations people engage in. Not all women who drink alcohol during pregnancy will have a child with FAS. However, no amount of alcohol is safe during pregnancy. For this reason the first author deemed it important to explore the occupational engagement of mothers who drink during pregnancy.

Within South African communities the collective nature of occupation is acknowledged ${ }^{3}$. Hence, maternal alcohol consumption should be viewed within the framework of the family, the community and the society. Questioning existing perspectives on this growing pandemic may lead towards exploring different structures and policies that can address occupational inequities ${ }^{4}$.

This research used an instrumental case study to draw attention to maternal alcohol consumption during pregnancy while illuminating contributing factors. Although the focus of the article is on alcohol consumption during pregnancy the literature will briefly provide information on FAS as a consequence of this occupation. Furthermore, the literature review provides a brief overview on the historical roots of excessive alcohol consumption as an entrenched cultural practice in some communities. Links are made with occupational science constructs such as occupational choice and occupational inequities to build an argument for taking a critical occupational therapy stance towards maternal alcohol consumption. The findings of the study illustrate the prominence of contextual factors and their influence on the occupational engagement of women who abuse alcohol during pregnancy. The argument is made for viewing maternal alcohol consumption as an imposed occupation, rather than only an individualised occupation.

\section{LITERATURE REVIEW}

Although FAS has internationally been reported in different racial groups $^{5}$ cases of FAS have predominantly been described among Native Americans, ${ }^{6}$ Aboriginal populations in Australia ${ }^{7}$ as well as indigenous populations of the Northern Cape and Western Cape Provinces of South Africa ${ }^{8,9,10}$. Alarmingly, the figures of a study done in a previously disadvantaged school in South Africa in the Western Cape and Northern Cape Provinces of South Africa revealed the highest prevalence in the world ${ }^{2}$.

The occurrence of this problem in the Western Cape has been linked to the history of farm workers. Historically, farm workers were employed by the Dutch and subsequently English colonialists. They used to be paid for their labour with tobacco, bread and wine". Although the effects of alcohol on the body were already commonly known, farm workers still received large amounts of low quality wine (with higher ethanol concentration) as payment. This was called the Dop system. The Dop system was widely practised on wine farms as well as deciduous fruit farms in the Western Cape $\mathrm{I}^{12,13,14,15}$. While the Dop system was initiated on wine farms, it later became an institutionalised practice in agriculture as a form of worker control. Even after the Dop System had become illegal in $1961^{16}$ this form of remunerating and controlling farm workers was still reported by farm workers in $1993^{17}$. While the 1928 Liquor Act managed to curtail the Dop system and promulgated legislation in I $96 \mathrm{I}$ made it illegal, the effects of the Dop system on many farm workers are still evident ${ }^{18}$. The legacy of the Dop System is deemed one of many imposed practices of colonisation.

Having been introduced into farming communities in the early years of colonial settlement in the Cape Colony" ", problematic alcohol use and alcohol dependence became part of the culture of not only the present generation of farm workers ${ }^{19,20,14}$, but also of the cultures of communities in informal settlements ${ }^{21}$. In combination with excessive drinking, poor living and work conditions resulted in poorer health status for those affected. Even in the absence of the Dop system, farm workers and their families were enmeshed in a cycle of poverty and dependence ${ }^{15}$. For people who lived on farms for many years, alcohol abuse offered a routine to the day, 
and also became an occupation around which many other activities were organised in the lives and culture of generations of farm workers and their families. Drinking also allowed for the emergence of a particular type of sociality - that of 'drinking friendships' and the excessive use of alcohol and binge drinking as a norm. Scully posited that the Dop system provided a unique cultural space for farm workers which farm owners could not share" .

Laliberte Rudman cites the critical potential of occupational science as the ability of occupational scientists to “... generate knowledge and raise awareness of how occupation is situated in social relations of power in ways that privilege some groups, while simultaneously disadvantaging others" $4: 300$. This critical potential of occupational science allows for the exploration of the socio-political aspects of maternal alcohol consumption within the historical context of South Africa. Women who drink during pregnancy and who come from low socio-economic contexts often grow up and live in unsupportive environments, but not enough is known about why they continue to consume alcohol during pregnancy. The intergenerational character of excessive drinking among farming communities has however, begun to emerge from longitudinal research studies.

Abrahams suggests that people "... are likely to choose occupations that are congruent with their perception of what is expected by society"22:188. Laliberte Rudman argues that our view of occupations should "... not negate the subjective experience of occupation or the agency individuals enact through occupation." She further suggests that we should work towards overcoming "... dichotomizing the subjective and socio-political"23:9. Occupation should thus be viewed as both subjective and socio-political. Given the great number of socio-economic factors negatively impacting on the everyday living conditions of South African marginalised groups it has become imperative to explore maternal alcohol consumption as occupation situated within a specific socio-historical and political context.

Prince states that farm workers are worse off than any other cadre of workers within the South African economy ${ }^{24}$. These workers are dependent on the employer for employment, accommodation and transport. Housing is often terminated at the end of work contracts. Women farm workers in particular, face the greatest challenges ${ }^{24}$. Besides having less job security than their male counterparts, women are often employed on a contract or seasonal basis and receive less income. The security of married women (or women who live with partners) is often dependent on the husband or partner.

Previous research on the characteristics of mothers who are at risk of having children with FAS documents person-specific factors. However, more than half of the associated characteristics are linked to the socio-economic environments in which these mothers live and work ${ }^{10,25,26,27,28}$. The information gathered thus far provides limited understanding of how culture, economy and politics perpetuate marginalisation amongst women who drink during pregnancy. In occupational therapy evidence of how culture for example, could reproduce occupational inequities as opposed to personal deficiencies ${ }^{4}$ in some communities is also evasive. One of the challenges with this distinction is that individuals are inextricably linked to their cultures and the contexts within which they live, work and socialise.

With this in mind this study focused on the occupational engagement of mothers who drink excessively during pregnancy. This shift in focus was intended to highlight the structural (economic, cultural and political) factors influencing occupational engagement during pregnancy. The main purpose was to explore alternative ways of preventing FAS.

\section{METHODOLOGY}

\section{Research Design}

A qualitative, instrumental case study ${ }^{29}$ was undertaken. Drawing from Stake's definition of what a case is ${ }^{30}$ each participant within the particular farm in which she was employed was regarded a bounded case and the occupational engagement of the participant explored as the phenomenon of interest. One advantage of case studies is that they can provide rich insights into the particular situations ${ }^{31}$ in which participants find themselves as well as the events and organisations with which they interact. This allowed the identification of unique occurrences within the lives of these women. Similarities and differences within and across the cases could be highlighted. Using the constructivist paradigm, through which the case study was approached in the current study, the participants were able to share and construct their stories while creating multiple realities. The subjective realities of participants were fore-grounded as the influence of context on the occupational engagement of the participants was considered ${ }^{32}$. Case study methodology is also known for considering the contextual conditions as well as clearly defining the boundaries between the context and the phenomenon ${ }^{29,30,33}$ namely occupational engagement of mothers.

\section{Participant Sampling}

From a list of 30 potential farms in the Western Cape, South Africa, four farms met the criteria required for purposive sampling. The criteria for the selection of farms were: free availability of alcohol and excessive alcohol drinking for women on a regular basis. Only two of the farms accepted the invitation to participate in the study. These two farms were then included in the study. At this stage, the study was common knowledge among farm workers in the area as it was introduced to workers by farm health workers and nurses at the local primary health care clinic. Recruitment of individual farm workers was conducted with the assistance of a clinic nurse who was familiar with the pregnancy status of the women, and to some extent, their drinking patterns. The background information letters about the research, consent forms and transcripts were translated in simple Afrikaans for the purposes of data collection and translated back into English for the research report. The information letters and consent forms were verbally explained to ensure voluntary informed consent. Three participants were recruited through purposive sampling.

The criteria for purposeful sampling were drawn from literature describing the traits of mothers who are at risk for having children with $\mathrm{FAS}^{20,25,26,27}$. Accounting for elements of balance and variety in age, stage of pregnancy and key socio-economic factors was of greater importance than a larger sample. The opportunity to learn from these cases took precedence ${ }^{29,30}$. More than one participant would therefore allow for a combination of characteristics (e.g. single, living with a partner, with or without children, poor education level and status of the farm on which they lived or worked). The first participant worked as seasonal worker, the second was unemployed and the third one worked as a permanent farm worker. The three participants worked on the two rural farms that accepted the invitation to participate in the study. Participants displayed interest in the study and were deemed able to share their stories in a way that would contribute to the phenomenon of interest within a case study approach.

Participants had to:

I. Have had one or more pregnancies or be pregnant at the time of research.

2. Have a self-reported history of excessive alcohol consumption during previous pregnancies. London cited levels of safe drinking at 210 grams of beer per week and dangerous drinking at more than 490 grams of beer per week ${ }^{14}$.

3. Live and/or work on a farm.

4. Be between the ages of 18 and 40 years of age. (The legal age for working and during which women can bear children with reasonable safety).

5. Have less than 10 years of formal education. (Low educational attainment was identified as one of the risk factors for alcohol use during pregnancy) ${ }^{34}$.

6. Have a monthly family income of RI 500 or less ${ }^{34}$.

7. Be Afrikaans or English speaking.

Pseudonyms were used to maintain confidentiality. 


\section{Data Collection}

Data were collected using semi-structured, in-depth interviews, a field journal and photographs. A minimum of two and a maximum of three interviews per participant, each with duration of between I hour 30 minutes and 2 hours were done. Interviews were conducted inside the homes of the participants. Occupational patterns and impressions on living conditions were noted in the field journal.

Special care was taken to interview participants while they were in a sober state. Having worked with mothers who consume alcohol during pregnancy earlier in her career, the first author was aware that participants' alcohol consumption during pregnancy introduced serious ethical dilemmas for clinical practice, and had to constantly juggle ethical obligations to alert health practitioners at the primary health clinic to possible risk to the unborn children, against preserving sufficient trust from participants to share their stories and experiences of being a mother and a partner. In addition, the first author ensured that participants constructed their own stories within their context. Although the interview process was guided by the participants' stories an interview guide was used as framework for possible questions that could be asked. Interview questions included activities that related to the occupations of work, self-care and socialisation. Interviews were audio recorded and transcribed verbatim in preparation for analysis.

Care was taken to maintain the integrity of the narrative during probing, as well as in later synthesising data towards final themes during analysis. An etic (outsider perspective) as well as an emic (insider perspective) was constantly interrogated as part of reflexivity, acknowledging the role of the first author as researcher but also as a woman and mother. The credibility of the findings relied heavily on the participants as storytellers to provide an accurate account of what they did on a daily basis at the time of the study and memories of what they used to do earlier in life. In addition to the interview time, participants' permission was sought to spend two mornings per week (three hours on each occasion) in the research context for the entire twelve months of the data collection phase. All photographs were taken during this stage. During this time observations were made on the living environments of participants within and around the home environment. In this way the researcher could become more familiar with the setting in which daily occupations took place. Spending time this way provided the researcher with "adequate submersion" in the research setting ${ }^{35: 217}$. The in-depth interviews, photographs and observation of participation provided for data triangulation, and enhanced the credibility of study findings ${ }^{29,36}$.

\section{Data Analysis}

During the first stage of analysis, open coding was used to code interview data and photographs. This stage involved within-case analysis ${ }^{29,30}$ of each individual case. Data was first disentangled (segmented) into single words or concepts. This method of identifying units of meaning helped the researcher to refrain from inputting personal motives, fears and unresolved issues to the collected data $^{37}$. Field notes and the researcher dairy were used to check that analysed data reflected the participants' stories as well as to triangulate data.

Following the first level of analysis were across-case analyses ${ }^{30}$. Similar and different features were identified and grouped together. Selective coding was used in the second stage of the analysis process, as the researcher began to focus on the occupational engagement of participants. Selective coding aided in elaborating on a core category (i.e. influences on previous and current occupations with particular focus on maternal alcohol consumption) around which the other developed categories could be grouped and through which they could be integrated ${ }^{30}$.

During the third stage of analysis the data was reconstructed back into a meaningful whole by grouping similar categories. Twenty nine categories were eventually collapsed into four themes.

\section{Trustworthiness}

An audit trail was established and maintained throughout the study to account for confirmability. Confirmability was further enhanced by discussing emerging codes, categories and themes with the research supervisor and other peer researchers. Towards the final stages of data analysis, a final member checking interview was arranged with only Nina and Wendy as Johanna had left for the Eastern Cape. Both participants confirmed the findings during the member checking interview.

Reflexivity was further facilitated by keeping a personal diary in which the researcher's subjective experiences of the research process were reflected upon. It was also used for making preconceived beliefs and opinions explicit ${ }^{38}$. The researcher's attitudes, perceptions, feelings and thoughts ${ }^{39}$ about the women, their living environments and their occupational engagement were also recorded. The personal diary was also a place in which the researcher could do self-inquiry as a way of clarifying her thoughts ${ }^{40}$. The advantage of keeping regular written accounts of the research process was that it enhanced reflexivity and ensured that the researcher was at all times aware of how her assumptions influenced the research process.

Ethics approval was received from the Human Research Ethics Committee of the University of Cape Town's Health Science Faculty with approval number: 2362004.

\section{FINDINGS}

Four themes were identified i.e. nothing comes easy, trying to make life bearable, rekindling hope and baking bread with little (see Table I for the themes and the categories of the themes).

\section{Nothing comes easy}

This theme captured the hardship experienced by participants. Challenges related to an unstable childhood and the harsh environments in which these women grew up. On the less developed farm, Nina and Johanna lived in small houses with no bathroom or kitchen. Although Johanna had her eldest child removed into foster care all three women cared for at least one child of their own at the time of the research. Communal toilets were provided on the premises but were dysfunctional for most of the time. Cooking in these settings was done on an open fire on the front porch or in a make-shift kitchen that doubled as a bedroom. On the more developed farm, Wendy lived in a house that was well-equipped.

\section{Table I: Findings}

\begin{tabular}{|c|c|}
\hline Themes & Categories \\
\hline $\begin{array}{l}\text { Als moet swaar gedoen } \\
\text { word } \\
\text { (Nothing comes easy) }\end{array}$ & $\begin{array}{l}\text { Being a woman means working hard } \\
\text { Starting to work at I } 3 \text { (years old) } \\
\text { Not having things of my own } \\
\text { lt's hard to live here... } \\
\text { Nêrens om te gaan, niks om te doen } \\
\text { (Nowhere to go, nothing to do.) } \\
\text { Just to get money } \\
\text { Losing loved ones } \\
\text { Loss of a life role } \\
\text { Unstable childhood }\end{array}$ \\
\hline $\begin{array}{l}\text { Trying to make this life } \\
\text { bearable }\end{array}$ & $\begin{array}{l}\text { Feeling helpless } \\
\text { Feeling bad about myself } \\
\text { My life is not worth much } \\
\text { I drink } \\
\text { Sleeping as a way of dealing with stress } \\
\text { Causing trouble when bored } \\
\text { To drink or not to drink } \\
\text { Not having control over my drinking } \\
\text { Fear of losing friends }\end{array}$ \\
\hline Rekindling hope & $\begin{array}{l}\text { I can think for myself } \\
\text { Need to take up lost occupations } \\
\text { Hoping for good things to happen } \\
\text { Reminiscing about better times }\end{array}$ \\
\hline Baking bread with little & $\begin{array}{l}\text { Helping others in need. } \\
\text { Having a routine around household chores } \\
\text { Having enough to do } \\
\text { Cleaning, cooking and caring for my } \\
\text { children }\end{array}$ \\
\hline
\end{tabular}


The participants' childhood experiences reflect drinking as an entrenched practice. Nina's childhood memories are that of physical violence, sexual violation and alcohol abuse:

My parents have been drinking since I can remember... and when they were drunk the fighting would start. My dad often beat my mom... until one day... he hit her and she fell..

(Silence)

They later told me that she died of brain damage. I was never going to be the same person after that day... (Pause)... He (dad) wanted me to take the place of his wife...I couldn't take it anymore then I left home...never to return.

After these life changing events Nina left home to meet the realities of adulthood at a very young age. She started experimenting with alcohol at the age of eleven and fell pregnant for the first time at fourteen years of age:

I tried it (alcohol) out for the first time when we (friends) decided to bunk school and get some cheap wine from the factory. Yes, that's how I started. Later we just got together to cool down (drink alcohol). It was like...you don't drink you don't have friends. Silence...... when I heard of the pregnancy I was shocked and disappointed at first...at least I now had a child of my own...

Nina's experimental drinking continued into adulthood:

After that I just never stopped. My friends and I would get together in the morning, just for a short one (short while to drink alcohol). Then maybe in the afternoon... and when he (partner) upsets me then I also drink or even when I'm angry... there's no-one to talk to when I have a problem and I can't trust the people around here.

Johanna explained how she usually plans to buy her drink when she receives her social grant once a month:

I explain to him (partner): Listen, I am first buying my drink, then everything else. That is my treat... I leisurely take my drink, then I do my shopping...it helps me to forget... but my child does not want to stay with me because of the drink.

Wendy's reason for drinking was because of boredom and not having anything else to do on the weekend:

There's nothing here...the closest mall is 60 kilometers away. Most youngsters don't have transport to go to the club, you know? So you're stuck. Drinking helps us to pass the time..

These quotes demonstrated how limited occupational opportunities (i.e. lack of constructive leisure opportunities, limited support services) and occupational deprivation can introduce and maintain excessive alcohol use as a form of occupational engagement in this context. Johanna's quote also reflects how alcohol consumption can give meaning and serve a purpose in her life. In Nina's case, growing up on a wine farm meant leaving school prematurely to start earning a small salary. Within their household, schooling was also not a priority, and since the nearest school was far away from Nina's home, chances of getting an education were significantly reduced. Nina thus left her childhood home to move into another farming community. Future employment possibilities were limited with her having a grade six education. Constructive leisure opportunities were lacking as she continued being part of the farming community as a farm worker on a different farm that provided better housing, but was isolated from facilities where she could pursue alternative leisure activities.

Being a woman in this context meant hardship. The following quote described Johanna's experience of what the life of a woman in her context is about:

.. being a woman in this place means having to work every day and all day long. When I think of my mother ... that was a woman who did not know (when to) rest. When I think of her and I look at my life now ... it's tough being a mother, because the mother just suffers all day long

\section{Nina said:}

It's the same thing every day: cleaning, cooking, and caring for the children, caring for the husband. And you can see where I have to cook everyday - there is no stove here! I make an open fire right there in the corner of the porch and I do all my cooking right there - come rain or sunshine! I do everything with this one (one month old baby) on my back ...

There's no running water here, so we fetch water from the tap down there (about twenty meters away). I carry wood from the vineyard and sometimes he (partner) will bring wood from town.

Wendy experienced hardship at an emotional level:

They (partners) don't care if they hurt you ... you're just a wife ... your life is just a struggle ...

Johannah seemed to be the only one that viewed living and working in the context as positive. She believed working hard and doing daily chores were an integral part of what makes a strong mother:

It is our job you see ... we have to do all these chores. This way we will have strong and healthy babies."

The stories of participants demonstrated key similarities. The data firstly suggested that opportunities were limited during their up-bringing. Secondly, as mothers, they had to negotiate a number of barriers (physical, emotional, economic and environmental) before, during and after pregnancy.

\section{Trying to make this life bearable}

The challenging conditions discussed in the first theme resulted in participants feeling helpless and worthless in the face of circumstances within which they found themselves. Wendy stated:

I don't care ... I I drink ... when I'm sad, I drink ... when happy, I drink ... what does it matter? When he (partner) makes me angry I drink and I feel better ... for a while at least ... I find my friends and we drink together - all the problems disappear.

Besides drinking excessively to try and help them deal with difficulties and make their lives bearable these women also drank alcohol as one of the entrenched forms of occupational engagement in this context. Johanna said:

People around here drink all the time. But if I stay here I'm at home all alone for most of the time ... he (partner) works all day and when he comes back he's in a plug (drunk). Then he picks a fight with me. It's hard, there's not much to do and most of the time I feel bad about all the mistakes I made in the past ... she (older daughter who was removed by social welfare) could have been living with me still ... if I did not mess it up".

\section{Wendy said:}

Agghh, drinking is the normal thing to do, everyday ... I want to stop, but before I find myself I had a drink with my neighbor or when my friends pick me up to go down to the stall. I can't help it ... who cares anyway ...

Nina listed her reasons for continuing to drink during pregnancy:

I considered stopping before ... but l'm gonna (going to) be an outcas ...(silence) ... you know, I still want to socialise with my friends and there's nothing else to do around here than pooling (contributing money) and cooling down (drinking) over the weekend ..

In summary, the three participants cited the following reasons for continuing to drink during pregnancy: the fear of losing friends, not having control over their drinking, and the difficulty in keeping to their decision to abstain when excessive drinking is the norm. Excessive alcohol use and hardship were entrenched in the matrix of the families and communities and experienced by participants as a normal part of life. Amidst the challenges presented by the context Johanna was the only one who expressed hope for her future.

\section{Rekindling hope}

Johanna expressed hope for a different future. The other two participants did not express future plans or hope of changing their situation. Johanna recalled her childhood and the values she was raised with: I can think for myself ... I was not born with alcohol. 
I become really sad. My daughter visits me once or twice a year. She does not want to be with her mother ... she says her mother drinks too much..

\section{now ... I have to remind myself: But you are a mother now ...}

She also recognised the value of lost occupations, but appreciates how challenging it could be to find her own way out of her current circumstances. While she is struggling to stop drinking she continues dreaming of a little garden and a neat home. She believes that if she could just stop drinking her dream of taking up some of her lost occupations may come true:

If I can just shake this habit ... We will have a little garden and a neat home ... there will be no alcohol, no fights ... we will be happy.

The last quote captured Johanna's strong sense of what she actually wanted for herself. Johanna shared that she had thought about the values her parents (who did not use any alcohol) taught her; to keep faith in her own abilities to create different possibilities and to uphold these values in the future. Johanna's recall of her childhood values demonstrates the positive influence of a supportive family during childhood. Her dream for a better home and stable family life helped her to get through the day. Her resolve to try and do better in life is clear as she imagined a future that is different, yet closer to the reality of her childhood. While all the participants described their lives as a constant fight for survival, Johanna was the only one who expressed the need for reclaiming the lost role as a mother to an older child who had been placed in foster care. She became excited at the prospect of seeing her child again and spoke about how her life would be much more meaningful with her daughter as part of her future.

\section{Baking bread with little}

Despite all the odds against them the participants were making a living while caring for their families. Their lives were made more meaningful by helping others in need within their immediate environment. This discovery challenged the researcher's initial perception of these women as only victims in their own environment. Despite living in an unsupported environment that limited their ability to meet their aspirations, these women's daily routines were well-established. The larger part of the day was spent securing food and accommodation or assisting neighbors with what they needed. Nina said:

It's not like I have enough to do one or two things for other people. If I did, I would've done it (given people what they need) anytime. But I don't have either. I also have to look and see where mine will come from today or tomorrow.

Despite spending a lot of time and energy on providing for their basic needs in a context where neighbours are also needy, Johanna often found herself having barely enough. Despite the shortage she was always willing to help others:

Once a woman came to ask me for a piece of food, but she came too late because I had just finished my food. I don't have an income either. I depend on my parents. I told her: 'You've come too late, I don't have anymore.' It looked as if that woman wanted to cry ...

Wendy stated:

I don't have a job, but I help the old people whenever I can. They struggle to get to the clinic and some of them have to wait for ages for the transport to pick them up. There was this old man at the clinic once ... he seemed to be lost ... I stayed with him until his daughter came looking for him ... yes, that's what I do around here.

Wendy loves children and often cared for the babies of mothers who had to return to work:

I look after them ... at least after one baby at a time, you know? She (neighbour) did not know what to do with the child and she asked me to look after him. He's good and listens to me (smiles). But she only earns a little money so she does not really pay me. She would bring some food or give me a piece of clothing as payment.

This fourth theme also serves as an analogy for the lives of these women. Baking bread with little is a phrase Johanna used to describe how she bakes bread in a pot on a two plate stove with a broken heat switch. She said:

I take a little piece of dough and place it in the bottom of the pot. I taught myself how to work this stove (with broken switches and no markings for temperature) ... within an hour the dough will rise and fill the pot to the brim. It makes beautiful, big bread. People who watch me do this want to know how I do it ...

The analogy of how this flat piece of dough rises to fill the pot is used to describe these women's ability to share the "little" they have with others by helping older people to get to the clinic and by baby-sitting the neighbour's baby for very little payment. These women showed an exceptional ability to passionately care for others despite their own disposition. Yet another parallel can be drawn from the phrase: "I taught myself how to work this stove" with the way in which these women manage to make a living in a challenging and dysfunctional context. It is clear that the women can almost say: "I taught myself how to survive in this context ..."

\section{DISCUSSION}

The notion of an imposed occupation is thus introduced in this paper, using the stories of Johanna, Wendy and Nina as case examples. Within these cases it is demonstrated how the culture of drinking in farming communities may influence the occupational engagement of mothers during pregnancy. The first author's work with these mothers who lived in a limiting context and who drink during pregnancy is suggesting imposed occupations to be those occupations that are sustained by hegemonic (oppressive) practices, norms and values that are embedded in the social matrix of society in which subaltern groups (marginalised groups who have lost their ability to voice their concerns or views) engage. Such occupations have a negative impact on personal and social health, well-being and the development of individuals and the social groups to which they belong.

Whereas Johanna recalled a positive childhood, Nina and Wendy experienced fragile family structures riddled with domestic violence and displacement. Adulthood and womanhood were generally described as challenging and filled with hardship and oppression. All three participants recounted positive contributions to their families and their neighbours. Although these three black women can be viewed as each having a set of positive personal attributes, they are still "positioned" within social structures that negatively impacted on their occupational possibilities. Before the new democratic dispensation that emerged in 1994, being a black woman in South Africa meant perpetual discrimination and oppression. Twenty years into the new democracy, historical institutionalised oppression has translated into intergenerational disadvantage and continuous marginalisation. The ways in which the social, economic and political conditions are structured perpetuate occupational injustice, occupational deprivation, occupational marginalisation and occupational imbalance ${ }^{41}$ for these women, to whom drinking is an entrenched occupation in the farming context. Excessive drinking as an entrenched cultural practice is often passed down from one generation to the next, rendering it as imposed occupation in the lives of women from some South African communities.

The work emanating from the first author's further doctoral research demonstrates how the culture of drinking in farming communities perpetuates alcohol consumption during pregnancy ${ }^{42}$. Findings by Devine and Nolan suggesting the interplay between identity and occupational engagement also refer to the influence of the social context ${ }^{43}$. Although the occupational identities of participants were not explored in this article their alcoholic consumption practices were influenced by the alcohol consumption norms in the wider farming community. This negative interplay between context and occupational engagement ${ }^{42}$ limits the occupational imaginings ${ }^{23}$ and occupational possibilities ${ }^{4,44}$ for these women. Furthermore, Galvaan revealed how occupational choice can be limited by oppressive historical, socio-economic and political conditions ${ }^{45}$. Cloete explored the further notion of continuation of occupations that are 
not of choice, but rather as a result of structural (cultural, economic and political) entrenchment ${ }^{42}$. She suggests that such occupations have been imposed.

According to Ratele, individual factors are heavily shaped by the social contexts in which individuals are located. If the social context lacks the necessary forces or elements that may create opportunities to engage differently in the environment, occupational possibilities $^{44}$ may be limited for individuals who live in marginalizing contexts. Abrahams suggests that people "are likely to choose occupations that are congruent with their perception of what is expected by society ${ }^{22: 188}$. Moanne in Ratele ${ }^{46}$ refer to the scars of bondage and identified the four consequential themes of oppression as: subjectivity, inhibited emotional expression, dysfunctional intergroup relations and higher prevalence of mental health issues. Excessive drinking has been partly described as a way of coping with hardship and oppression in the current paper, but also as an expression of the influence of contextual factors pushing for excessive drinking. Limited opportunities coupled with hardship in the lives of these women resulted in excessive drinking as one of many occupations that were imposed upon them. Drinking is thus expressed as an imposed occupation.

Johanna's story demonstrates that she was still able to aspire to a life in which alcohol abuse had less prominence, where she could reconnect with previously held occupations. However, the limited support in her context presented challenges for Johanna to pursue a different future without additional external support from her environment. She emphasised that she was not raised within a context where abuse alcohol was prevalent. However, the context in which she found herself as an adult pressed for excessive alcohol abuse. Her individual aspirations of a better life were constantly frustrated by the lack of opportunity to explore new possibilities. The third theme illuminates the dichotomy between the individual and the social as Johanna's individual agency is contrasted with Nina and Wendy's silence on future possibilities. Johanna is a stark reminder of the participants as human beings, with hopes and aspirations as she expressed hope for a different future.

All three participants have learnt to maintain daily routines of securing food and security and building community with friends and family in a context where excessive drinking is the norm. Although participants were aware of the harmful effects of drinking during pregnancy, they continued engaging in excessive drinking for different reasons. Johanna's story demonstrates the complexity between environmental structure and individual agency while Nina and Wendy cited reasons that related to familial and social factors. Their stories demonstrate the need to be aware of individual agency but focus more specifically on the main social issues that are related to maternal alcohol consumption as occupation ${ }^{23,47,48}$. Furthermore, despite individual agency and the ability to imagine different futures, sociopolitical factors can limit future occupational possibilities ${ }^{44}$.

\section{LIMITATIONS OF THE STUDY}

As a result of constant relocation due to job insecurities it was a challenge to identify suitable participants who would commit to doing the number of interviews required. The study design did not originally provide for the involvement of participants who were illiterate and adjustments had to be made along the way to accommodate for this. Johanna could not be located to do member checking as she had moved back with her parents in one of the rural areas of the country. As a result, the credibility of the findings may have been diminished as it was only based on the feedback of two of the three participants.

\section{CONCLUSION}

Maternal alcohol consumption during pregnancy is commonly seen as the individual's way of coping with challenging socio-political realities. This study suggests that it can be understood as equally shaped by the context (i.e. historical, cultural, political and -economic factors). Within the health promoting efforts of occupational therapy the individualisation of occupation should be problematised. The broader sociopolitical processes through which occupational possibilities of mothers who consume alcohol during pregnancy should be equally considered. Enhancing our understanding of the influences on the occupational repertoire of mothers who are at risk of exposing their unborn babies to alcohol may contribute to FAS prevention initiatives. Furthermore, understanding alcohol consumption during pregnancy as an occupational effort allows us to identify imposed occupations by appreciating the influence of socio-political and historical factors.

\section{REFERENCES}

I. Bailey, B.A. \& Sokol, R.J. Pregnancy and alcohol use: Evidence and recommendations for prenatal care. Clinical obstetrics and gynecology.2008; 5 I (2): 436-444.

2. McKinstry, J. Using the past to step forward: Foetal alcohol syndrome in the Western Cape province of South Africa. American Journal of Public Health. 2005; 95(7): 1097-1099.

3. Adams, F. \& Casteleijn, D. New insights in collective participation: A South African perspective. South African Journal of Occupational Therapy. 2014; 44(I): 81 - 87.

4. Laliberte Rudman, D. Enacting the critical potential of Occupational Science: Problemtaizing the "Individualization of Occupation". Journal of Occupational Science. 20I 3; 20(4): 298-3 I 3.

5. Bingol, N. , Schuster, C. , Fuchs, M. , losub, S. , Turber, G. , Stone, R.K. \& Gromisch, D.S. The influence of socio-economic factors on the occurrence of Foetal Alcohol Syndrome. Advances in Alcohol and Substance Abuse. 1987; 6(4): 105-108.

6. Mulligan, C.J., Robin, R.W., Osier, M.V., Sambuughin, N., Goldfarb, L.G. \& Kittles, R.A. Allelic variation at alcohol metabolism genes (ADHIB, ADHIC and ALDH2) and alcohol dependence in an American Indian population. Human Genetics. 2003; I I 3: 325-336.

7. Goh, Y.I. FASTRAC: The right track but the wrong engine: A critical review of Foetal Alcohol teaching and research awareness campaigns. Journal of FAS International. 2006; 4(e23): I-3.

8. May, P.A. A multi-level comprehensive approach to the prevention of fetal alcohol syndrome (FAS) and other birth related defects (ARBD). International Journal of Addiction. 1995; 30: I549- 1602.

9. Rendall-Mkosi, K., Morojele, N., Zama, M., London, L., Matjila, J., Jacobs, K., Olorunju, S., Davids, A. et al. Comprehensive FAS Prevention Programme Model Development in South Africa. Second International Conference on Foetal Alcohol Spectrum Disorder: Research, Policy, and Practice around the World. Victoria, Canada, 2007.

10. Viljoen, D. Croxford, J., Gossage, J.P., Kodituwakku, P.W., \& May, P.A. Characteristics of mothers of children with fetal alcohol syndrome in the Western Cape Province of South Africa: A case control study. Journal of Studies on Alcohol. 2002; 63,6-I7.

II. Scully, P. Liquor and labour in the Western Cape, 1870-1900. In Liquor and Labour in Southern Africa. J. Crush \& C. Ambler, Eds. Athens: Ohio University Press, 1992: 56-77.

I2. Crome, I.B. \& Glass, Y. The Dop system: a manifestation of social exclusion. A personal commentary on "alcohol consumption amongst South African workers: a post- apartheid challenge, by L. London 1999. Drug Alcohol Dependence. 2000; 59: 207-208.

I3. London, L., Nell, V.,Thompson, M.L. \& Myers, J.E. Effects of longterm organophosphate exposures on neurological symptoms, vibration sense and tremor among South African farm workers. Scandanavian Journal of Work and Environmental Health. 1998; 24(I): 19-29.

14. London, L. The "dop" system, alcohol abuse and social control amongst farm workers in South Africa: a public health challenge. Social Science \& Medicine. 1999a; 48: |407- |4|4.

15. London, L. Addressing the legacy of the Dop System: Tackling alcohol abuse among South African farm workers. Urban Health and Development Bulletin. 2(I). Cape Town: Medical Research Council, 1999b. Also available on http://www.sahealthinfo.org

16. Department of Trade and Industry. Liquor Act. Cape Town: Government Printers. 1963.

17. London, L., Saunders, D. \& Te Water Naude, J.. Farm workers in South Africa - The challenge of eradicating alcohol abuse and the legacy of the 'Dop' System. South African Medical Journal. 1998;88(9): 1092-1094.

18. London, L. Alcohol consumption amongst South African farm workers: A challenge for post-apartheid health sector transformation. Drug and Alcohol Dependence. 2000; 59: 199-206.

19. De Kock, A. E. Fruit of the vine, work of human hands. farm workers 
and alcohol on a farm in Stellenbosch, South Africa. (Unpublished M.A. Social Anthropology). University of Cape Town, 2002.

20. May, P.A., Brooke, L., Gossage, J.P., Croxford, J., Adnam, C., Jones K.L., Robinson, L., \& Viljoen, D.. Epidemiology of FAS in a South African community in the Western Cape Province. American Journal of Public Health. 2000; 90(12): 1905-1912.

21. Ross, F.C. Raw life, new hope: Decency, housing and everyday life in a Post- Apartheid community. I st ed. Cape Town: UCT Press, 2010.

22. Abrahams, T. Occupation, identity and choice: A dynamic interaction. Journal of Occupational Science, 2008; 15(3): 186-189. doi: I080/I442759|.2008.9686629

23. Laliberte Rudman, D.. Embracing and enacting an Occupational Imagination": Occupational Science as transformative. Journal of Occupational Science. 20 I4; doi: 10.1080/1442759I.2014.888970

24. Prince, C. Conditions on farms: A Draft paper (Desktop Study). Unit for Social Research. Department of Social Services and Poverty alleviation. South Africa, 2004.

25. Connor, P.D., Sampson, P.D., Bookstein, F.L., Barr, H.M., \& Streisguth, A.P. Direct and indirect prenatal alcohol damage on executive function. Developmental Neuropsychology. 2000; 18: 33 I-354.

26. De Vries, J., \& Walker A. Fetal alcohol syndrome through the eyes of parents. Addiction Biology. 2004; 9(2): II9-120-I 26.

27. Jacobson, J.L., Jacobson, S.W., Sokol, R.J., Martier, S.S., Ager, J.W., \& Kaplan-Estring, M.J. Teratogenic effects of alcohol on infant development. Alcohol, Clinical and Experimental Research. 1993; 17: 174-83.

28. Stratton, K., Howe, C., \& Battaglia, F. Fetal alcohol syndrome: Diagnosis, epidemiology, prevention and treatment. Washington DC: National Academy Press, 1996.

29. Baxter, P. \& Jack, S. Qualitative Case Study Methodology: Study Design and Implementation for Novice Researchers. The Qualitative Report. 2008; 13(4): 544-559.

30. Stake, R. E. Multiple case study analysis. New York: Guilford Press, 2005.

31. Rule, P., \& John, V. Your Guide to Case Study Research. Pretoria: Van Schaik Publishers, 20II.

32. Ponterotto, J.G. Qualitative research in counselling psychology: A primer on research paradigms and philosophy of science. Journal of Counselling Psychology. 2005; 52(2): 126-I36.

33. Yin, R.K. Case Study Research: Design and Methods (3rd Ed.). Thousand Oaks, CA: Sage, 2003.

34. Croxford, J. \& Viljoen, D. Alcohol consumption by pregnant women in the Western Cape. South African Medical Journal. 1999; 89(9):962-965.

35. Krefting, L. The culture concept in the everyday practice of occupational and physical therapy. Physical and Occupational Therapy in Pediatrics. 1991; II(4): I-16.

36. Pope, C. \& Mays, N. Qualitative research in health care. 3rd ed. Oxford: Wiley-Blackwell, 2006.

37. Finlay, L. Mapping Methodology. In L. Finlay \& C. Ballinger (Eds). Qualitative Research for Allied Health Professionals: Challenging Choices. Ist ed., 2006: 2I-22-29.

38. Ortlipp, M. Keeping and using reflective journals in the qualitative research process. Qualitative Report, 2008; 13:695-705. Retrieved February 18, 2014 from: http://www.nova.edu/ssss/QR/QRI3-4/ ortlipp.pdf.

39. Finlay, L. \& Gough, B. Reflexivity: A practical Guide for Researchers in Health and Social Sciences. Wiley, London, 2003.

40. Fischer, C. T. Bracketing in qualitative research: Conceptual and practical matters. Psychotherapy Research. 2009; 19(4-5): 583-590.

4I. Wilcock, A. A. \& Townsend, E. A. Occupational justice. In E. B. Crepeau, E. S. Cohn \& B. A. Schell (Eds.), Willard \& Spackman's Occupational Therapy (I I th ed.), Philadelphia: Lippincott, Williams \& Wilkins, 2009: 192-199.

42. Cloete, L.G. Developing appropriate Fetal Alcohol Spectrum Disorder in a rural community in South Africa. Phd Thesis, University of Cape Town; 2012.

43. Devine, R \& Nolan. C. Sexual identity and Human Occupation: A qualitative exploration. Journal of Occupational Science. 2007; 14(3): |54-161.

44. Laliberte Rudman, D. Occupational Terminology. Journal of Occupational Science. 2010. doi: 10.1080/14427591.2010.9686673.

45. Galvaan, R. Occupational choice: The significance of socio-economic and political factors. In G.E. Whiteford \& C.Hocking (Eds.), Occupational Science: Society, Inclusion, Participation. West Sussex, UK: Blackwell, 20I2: I52-162.

46. Ratele, K., Duncan, N., Hook, D., Mkhize, N., Kiguwa, P., \& Collins, A. Self, Community and Psychology. Lansdowne: UCT Press, 2004.

47. Angell, A. M. Occupational-centered analysis of social difference: Contributions to a socially responsive occupational science. Journal of Occupational Science. 20 I2. doi: 10. I080/ I442759I.2012.7I I 230

48. Hocking, C., \& Whiteford, G. E. Introduction to critical perspectives in occupational science. In G. E. Whiteford \& C. Hocking (Eds.), Occupational science: Society, inclusion, participation. West Sussex, UK: Blackwell, 2012: 3-7.

http://dx.doi.org/ I 0.17 I 59/23 I 0-3833/20 I 5/v45no l a6

Corresponding Author

LG Cloete

Email address: lizahn@sun.ac.za 